desde la academia

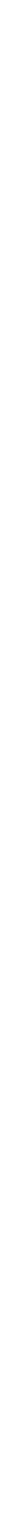

\title{
Arte y corporeidad, una apuesta para el diálogo intercultural
}

Magda García von Hoegen 


\section{RESUMEN}

En contextos sociales complejos, donde existen múltiples visiones de vida, procedencias étnicas, sectores sociales que aún no han podido integrarse ni llegar a conocerse, se hace necesario repensar los procesos comunicativos tomando como punto de partida el ser humano integral.

El conocimiento maya aporta a ello el concepto del Jun Winäq, la persona plena en todas sus dimensiones. Este elemento permite crear nuevos puentes de diálogo en los que exista interacción profunda entre personas diversas.

En este sentido, el presente trabajo propone el arte como plataforma de comunicación que toma en cuenta las áreas emocionales y espirituales humanas, además de las elaboraciones mentales. Desde la corporeidad como código, se parte de los supuestos de que el cuerpo va delante de los procesos intelectuales y que existe una mente encarnada que brinda elementos importantes para superar estadios de confrontación y construir relaciones solidarias.

A través de la danza como camino entre nodos de redes comunitarias, música como praxis social, teatro como vía para la encarnación de lo diverso y escritura como puente entre intertextualidades, se desarrolla un proceso de creación artística con jóvenes de Alta Verapaz, Guatemala. En las obras artísticas producidas, se plasman sus propuestas para la convivencia ante los desafíos actuales.

Palabras clave: cultura, interculturalidad, diálogo, convivencia, arte, redes, corporeidad, somática, plurilógicas, conocimiento maya.

\section{Huellas de la historia en los cuerpos}

Es cierto que a nosotros nos sucedió esta violencia en nuestro lugar, ya no queremos que vuelva a suceder en los días que vienen frente a nosotros [...] Ya no queremos que vuelva a suceder, ya no queremos que les suceda a nuestros hijos. (ODAHG, declarante 6, 1997)

Borro de mi cuerpo la muerte y el signo de la violencia, los símbolos de tristeza. Cómo quisiera que todo eso se borrara de la vida. Borré la desigualdad porque quiero que todos me quieran como soy. (Joven Tactic, Alta Verapaz, 2013)

La primera frase fue expresada por una habitante de Jolomuch, comunidad situada en Alta Verapaz, Guatemala, en un testimonio brindado a la comisión encargada de la elaboración del informe para el Proyecto Interdiocesano de Recuperación de la Memoria Histórica (REMHI). Dicho testimonio hace referencia a los hechos de violencia vividos entre los años 1982 a 1985, período en que fueron más fuertes las políticas de terror implementadas por el Estado durante la guerra interna.
ABSTRACT

In complex contexts where are multiple visions of life, ethnicities and social sectors that have not yet been integrated, is necessary to rethink the communicative processes taking the whole human being as a starting point.

The Mayan knowledge provides the concept Jun Winäq that means the whole person in all dimensions. This element gives bases to create new spaces for dialogue, including deep interactions in social diversity.

This paper focuses on art as a communication platform, which takes into account the emotional and spiritual human aspects, besides the mental elaborations. From corporeity as a code, it is assumed that the body goes beyond the intellectual processes; an embodied mind exists, and provides important elements to overcome confrontation, and build supportive relationships.

Through dance as a path between nodes of community networks, music as social praxis, theater as an experience of otherness, and writing as a bridge between intertextualities, this research develops a process of artistic creation with youth from Alta Verapaz, Guatemala. From this space and the artistic works produced, boys and girls express their proposals for coexistence, facing the current social challenges.

Keywords: culture, interculturality, dialogue, coexistence, art networks, corporeity, somatic, Mayan knowledge.

Parece que el tiempo se ha detenido y, con palabras similares, una joven del municipio de Tactic, Alta Verapaz, en 2013 expresa la misma súplica por el cese de la violencia. Aunque hoy ya no se vive el terror como política de Estado, este sigue presente por otras causas, como el crimen organizado, el narcotráfico y la violencia común. ${ }^{1} \mathrm{Al}$ final, el mensaje de ambas mujeres es el mismo: una contundente exigencia de que cese el irrespeto por la vida.

Las dos expresiones anteriores evidencian que el país aún no ha superado las causas estructurales que históricamente han provocado pobreza, división y enfrentamiento; también sacan a luz la necesidad de construir puentes de diálogo y convivencia que permitan establecer lazos de confianza y reciprocidad. Esto es muy complejo en un contexto donde la diversidad apenas se vislumbra como un factor que potencia el desarrollo integral de los habitantes del país. Es un entorno aún marcado por el hermetismo, la desconfianza y el miedo, consecuencias de treinta y seis años de enfrentamiento.
Magda García von Hoegen::

Instituto de Estudios Humanísticos, Universidad Rafael Landivar, Guatemala magarciav@url.edu.gt

Recepción: diciembre 2013 Aceptación: abril 2014.

$1::$

A partir del análisis de noticias publicadas en medios nacionales y departamentales, se da

seguimiento a las problemáticas sociales de la región. Desde el 2009, se detectó la presencia de Los Zetas, grupo mexicano. En el año 2010, el gobierno de Álvaro Colom decretó estado de sitio en Alta Verapaz. La situación fue aparentemente superada: $\sin$ embargo, las redes de narcotráfico y crimen siguen operando. Una serie de violaciones a niñas de entre 12 y 19 años, principalmente en Cobán y Tactic, encendieron la alerta. Dada la falta de credibilidad de las instituciones del Estado ante los pobladores, los miembros de diversas comunidades han tomado el ejercicio de justicia por sus manos. Entre 2012 y 2013, se registraron dos linchamientos, uno en el municipio de Tactic y otro en Cobán. En las referencias

bibliográficas, se encuentran las principales noticias recabadas en medios de comunicación escritos. 
El presente trabajo pretende construir plataformas integrales de diálogo que, mediante el arte y la corporeidad como código comunicativo, contribuyan a la reconstrucción de microtejidos sociales.

El 29 de diciembre de 1996 se consolida la firma de los Acuerdos de Paz Firme y Duradera. El tercer punto sustantivo de dichos acuerdos se refiere a la identidad y a los derechos de los pueblos indígenas y establece este aspecto como fundamental y de trascendencia histórica para la construcción del presente y del futuro del país. Asimismo, se reconoce a Guatemala como nación pluriétnica, multilingüe y pluricultural (COPREDEH, 1998).

A casi veinte años de la firma de estos acuerdos, Guatemala aún tiene mucho camino por recorrer para convertirse en una sociedad incluyente, tanto en las relaciones de la vida cotidiana como en las políticas públicas y decisiones de Estado.

Ante el panorama planteado, cabe preguntarse qué

El grupo de escritura se conformo por 10 varones y 14 mujeres; de ellos, 10 eran mestizos y 14 indígenas (2 q'eqchi', 2 achíy 10 pocomchi), y la franja etaria predominante fue entre los 15 y los 16 años (16 individuos). El grupo de teatro estuvo integrado por 8 varones y 18 mujeres; 22 eran indigenas mayoritariamente pocomchi (12); 11 participantes tenian 17 años y 6 tenian 16 años de edad. El grupo de música tuvo 4 varones y 12 mujeres, en total 11 indigenas, de los cuales 10 pertenecian al grupo étnico pocomchi'; 4 participantes tenían 16 años y 5,18 ; los demás se distribuian entre los 14 y los 40 años de edad. El grupo de danza fue el más numeroso y contó con mayoría de mujeres $(23$ y solo 4 varones); las edades predominantes fueron de 15 a 17 años, y, de los 20 participantes indigenas, 17 eran del grupo étnico pocomchi. final de trabajo de campo, se decidió trabajar con jóvenes de entre 15 y 19 años de edad, todos nacidos en la coyuntura de la firma de los Acuerdos de Paz. El estudio se desarrolla en el departamento de Alta Verapaz, al norte de Guatemala.

Dicho departamento es complejo en cuanto a su composición étnica, porque conviven diversos grupos mayas. Los grupos mayoritarios son el q'eqchi' y el pocomchi, pero también hay presencia de achis, además de grupos indígenas que han migrado a la región y otros que volvieron retornados a Guatemala luego del conflicto interno. La región también tiene población mestiza y descendientes de extranjeros asentados en este territorio desde el siglo XIX. Estadísticamente, la composición étnica de la población tiene las siguientes proporciones: 79,9\% de población q'eqchi', 10,9\% pocomchi', 7,4\% mestizo y un 1,7\% clasificado como otros (Arriola y Escobar, 2010).

Los jóvenes, sujetos de estudio de esta investigación, confluyen en el municipio de Tactic, de población mayoritaria pocomchi, donde se forman para ser maestros. Sin embargo, en la institución educativa a la que asisten conviven con jóvenes provenientes de diversas comunidades de Alta Verapaz. Se consideró idóneo trabajar con este grupo porque es representativo de la diversidad cultural y étnica.

Se trabajó con noventa y tres jóvenes, divididos en cuatro áreas artísticas: escritura, teatro, música y danza. ${ }^{2}$

La complejidad de la convivencia en la región no se reduce a las generalizaciones que surgen a primera vista: la dicotomía mestizo-indígena. Históricamente en el territorio de Alta Verapaz, el grupo indígena con mayor fuerza y dominio ha sido el q'eqchi. Los grupos pocomchis han desarrollado estrategias identitarias para mimetizarse con el grupo indígena dominante. Sin embargo, al profundizar en el concepto de sí mismos, reivindican y valoran su identidad como grupos diferenciados.
En Alta Verapaz han recrudecido las acciones violentas contra jóvenes vulnerables, especialmente mujeres. En este entorno, los jóvenes construyen su visión de presente y futuro no solo en las coyunturas locales, sino a través de la tecnología, que les permite un constante contacto con realidades propias y externas. Este contexto social e histórico tan complejo presenta grandes desafíos para establecer puentes de diálogo y de conocimiento del otro cultural, en espacios donde el prejuicio, la reserva y la estigmatización se hayan superado. 
Guatemala todavía está en transición de sanarse como sociedad. Existen desafíos importantes para encontrar puntos convergentes entre sectores polarizados y definir objetivos comunes, que se traduzcan en acciones de reconciliación y convivencia:

La reconciliación no es el olvido para que los recuerdos no dañen, ni es el perdón para ignorar agravios. Sin memoria no hay futuro ni identidades ciertas. [...] No se puede olvidar lo que no se conoce ni perdonar sin saber a quién se perdona. La reconciliación es el restablecimiento de las redes naturales de cohesión social en el seno de la comunidad, el regreso al fuero intimo de las relaciones sociales de cooperación, de ayuda mutua, fraternidad. Es lo que se llama la "recuperación del tejido social" (Torres Rivas, 2007, p. 34).

La reconciliación, como proceso fundamental de los Acuerdos de Paz y como elemento central para la reconstrucción del tejido social, es un asunto pendiente para el Estado y la ciudadanía. En ese sentido, el presente trabajo se enfoca en el fortalecimiento de microtejidos sociales, toma la corporeidad como punto de partida y el arte como proceso de diálogo, para generar acciones concretas de transformación individual y colectiva.

Según Gularte (2009), el ejercicio de la comunicación en Guatemala plantea retos importantes; uno de ellos, construir diálogo en una sociedad de posguerra, donde el enfrentamiento anuló la confianza entre sus miembros. Esto trajo como consecuencia una cultura de miedo, que se manifiesta hoy tanto en la falta de libre expresión como en las resoluciones violentas de conflictos.

Otro desafío es la construcción de la comunicación en una sociedad donde se enraízan el racismo y la discriminación. Si bien la Constitución expresa que "en Guatemala todos los seres humanos son libres e iguales en dignidad y derechos" (artículo 4) y "reconoce el derecho de las personas y de las comunidades a su identidad cultural de acuerdo a sus valores, su lengua y sus costumbres" (artículo 58), el país aún tiene mucho que recorrer para erradicar el rechazo a la diferencia en las realidades cotidianas y para lograr espacios de convivencia en la diversidad.

Gularte (2009) también sostiene que es necesario crear estrategias de diálogo en un país que enfrenta altos grados de pobreza, desinformación y centralización del poder. La comunicación debe contribuir a la transformación de actores en sujetos sociales, capaces de crear procesos de desarrollo endógeno y redes de cooperación, cohesión entre sus miembros y habilidades de negociación con sus autoridades.

Asimismo, dicho autor plantea la necesidad de construir procesos comunicativos que tomen en cuenta la globalización y las nuevas tecnologías, y al mismo tiempo mantengan la identidad propia.

\section{Raíces conceptuales}

Hacemos nuestro tejido existencial agarrados de los hilos guiadores que enmarcan nuestro actuar humano. (Chochoy et al., 2007, p. 125)

Para la búsqueda de plataformas de diálogo se toman como punto de partida los conceptos convergentes entre el pensamiento maya y las teorías sobre visión simbólica de la cultura. Si se habla de diversidad de pensamiento y de cosmovisión, no es posible adoptar solamente fundamentos teóricos provenientes de la cultura occidental.

Se hace necesario indagar qué aporta el conocimiento maya en cuanto a su manera de concebir el tiempo y el ser humano. Este trabajo pretende poner en diálogo elementos teóricos de distintas perspectivas culturales. 
Para ello se analiza la propuesta de las “plurilógicas". Mignolo (2006), desde esta perspectiva, cuestiona la intención de absolutizar el saber, la pretensión de un pensamiento único, propio del período colonial del siglo XVI, que valida el conocimiento desde los criterios de la postura occidental. Como contrapropuesta, plantea el concepto de "geopolítica del conocimiento".

Sobre el concepto anterior, sostiene que existen otras epistemologías que responden a las particularidades del territorio, la historia y la situación en que fueron concebidas. Esto indica que el conocimiento se genera desde cada lugar, respondiendo de manera distinta a la realidad y también a elementos culturales propios del contexto en que surge.

Mignolo propone la consideración de posturas plurales, múltiples lógicas, cuyo cimiento es un saber situado en un contexto geográfico y cultural específico.

Se parte de esta propuesta para entender qué lógicas de concepción de la vida existen en Guatemala y para proponer nuevos procesos de comunicación en la diversidad cultural.

La cosmovisión maya construye el conocimiento a partir de una interconexión entre el tiempo, el espíritu y la materia. La matemática vigesimal contiene estos elementos y se ha construido sobre la base del cuerpo humano, que cuenta con veinte dedos. El veinte representa el ser completo, denominado Jun Winäq: "Un sistema entero, matemática humana entera. La matemática decimal es solo la mitad de la cuenta" (García et al., 2009, p. 23).

La idea del Jun Winäq lleva a cuestionarse cuáles son las vías que permiten un espacio comunicativo donde estén presentes la emocionalidad, la espiritualidad, las subjetividades, además de los pensamientos.
La sociedad guatemalteca demanda la construcción de nuevos códigos, con significados comunes, que permitan avanzar hacia la convivencia y el diálogo.

Como sucede con el arte y el juego, la comprensión es la condición permanente de toda comunicación. No se trata únicamente del conocimiento del código lingüístico sino de una constelación de códigos que constituyen la dimensión cultural de la existencia humana y que presuponen un interpretante "in-formado" (formado en la cultura propia) que sea capaz de encontrar el sentido. La exigencia de un intérprete que capte no solo lo que se dice sino lo que se quiere decir implica pensar un sujeto histórico-social que responde a una localización precisa: el intérprete pertenece a una cultura -que fija regulaciones-, a un tiempo histórico - que traza un horizonte de sentido- y a un espacio social -desde donde se plantea la pregunta- que recortan el horizonte total para operar sobre él una apropiación fragmentaria [...] Sobre la base de un conjunto de significaciones en común, se producen apropiaciones particulares, impugnaciones, argumentaciones y consensos (Papalini, 2007, pp. 27-28).

A partir de la experiencia artística, en este trabajo se aborda, como sostiene Papalini, una constelación de códigos que toman en cuenta la subjetividad, la historia de vida y la cultura de los sujetos de estudio. Una memoria histórica viva, es decir, en constante reelaboración y transformación, no como un conjunto de hechos rígidos cristalizados. Desde la agencia, se constituyen sujetos históricos, con conciencia de sí y de su pasado, capaces de resignificarlo para construir un nuevo presente y decidir su futuro.

Esta historia viva se reconfigura en la interacción cotidiana, y puede comprenderse desde múltiples códigos vivos también, insertos en la integralidad del 


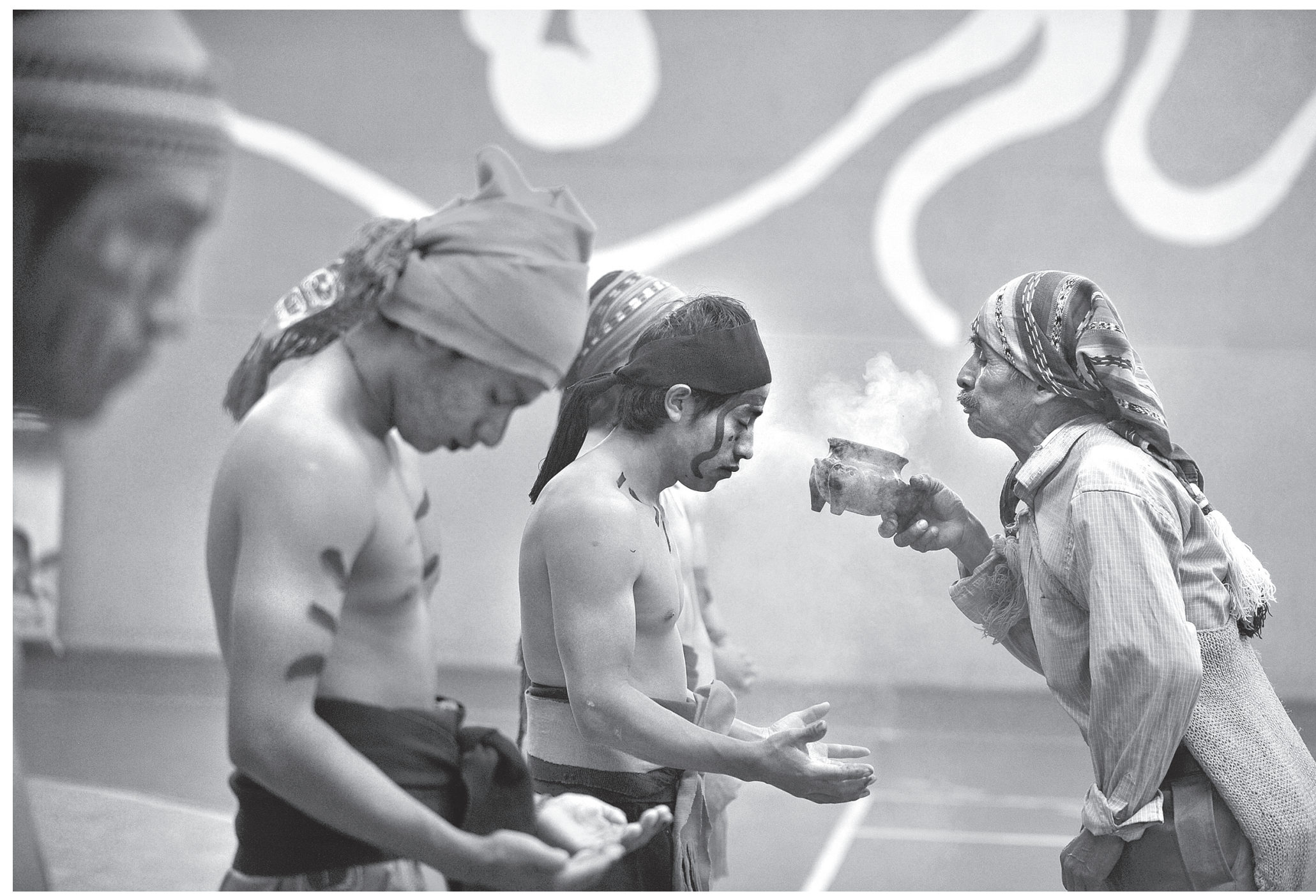

ser humano, que implica subjetividades a partir de las que se construyen saberes y conocimiento. Para ello, el pensamiento maya da luces importantes.

Este pensamiento considera que el saber se configura con el pensar y el sentir y que implica un proceso de elaboración interna, donde se relacionan las voces interiores y las externas. De esta cuenta, además de recibir información desde afuera, se valora un "maestro interno", que entra en diálogo con los estímulos exteriores. Se aprende de la naturaleza y de todos sus seres, de la vivencia, y se toma la tradición oral como fuente de transmisión de sabiduría.

Más allá de estas notables diferencias entre el pensamiento occidental y el maya, a mi juicio existe un punto de convergencia para explicarse la cultura, el conocimiento y la convivencia: el concepto de red.
El símbolo de la telaraña está presente en la cosmovisión maya en de la idea del $k$ 'at, que significa el tejido de la vida, el entramado, la red. Este símbolo incluye en sí mismo la posibilidad del conflicto, representado a partir de los "enredos", es decir, las tensiones en las relaciones humanas, la confusión.

La constitución del Universo está establecida en redes de relaciones, agrupaciones con relacionamiento y afinidad. [...] El fuego esencial de la vida es la cualidad de construir momento a momento el tejido de relaciones, pues el encuentro de todas las relaciones da la plenitud. [...] La fragmentación diluye, enfría y paraliza (Chochoy et al., 2007, pp. 96-97).

En el pensamiento occidental, la concepción simbólica de la cultura es, en esencia, un proceso semiótico, que
Foto: Johan Ordonez, AFP. Ciudad de Guatemala, febrero 2010 
emplea la analogía de tejido o urdimbre de significaciones para definirla.

Esas significaciones dan luz para interpretar una realidad que no puede ser analizada desde generalidades, sino que responde a una red de significaciones. "El análisis consiste pues en desentrañar las estructuras de significación [...] es una multiplicidad de estructuras complejas, muchas de las cuales están superpuestas o enlazadas entre sí, estructuras que son al mismo tiempo extrañas, irregulares, no explícitas” (Geertz, 2001, p. 24).

Ambas perspectivas, maya y occidental, hablan de hilos y entramados, de significados que se entretejen en la profundidad de la vida, que se concretan y se reestructuran a través de las interacciones humanas. El proceso comunicativo permite la realización de tales interacciones; por tanto, la cultura es un proceso eminentemente comunicativo. Tanto el pensamiento maya desde el símbolo del $k$ 'at como el planteamiento occidental de la cultura como proceso simbólico apelan a la construcción de alianzas y caminos entre los nodos de una red. Esa red es el tejido social.

Cabarrús (2008) define el tejido social como un entramado de relaciones que facilitan la convivencia y la vida en sociedad. En este contexto, el diálogo es un elemento cohesionante para mantener unida la comunidad.

El autor expresa que el tejido social es un sistema que agrupa ideas, necesidades, intereses y organizaciones bajo normativas específicas. Estos cuatro elementos conforman la urdimbre vertical básica del tejido. Estas hebras son unidas por tramas horizontales vitales: las normas y la identidad. En todo ello, es fundamental el desarrollo de la habilidad de comunicación.

Cabarrús denomina a este proceso "hacer política desde el sin poder", cuyo fundamento es un actuar estratégico que logre una intercomunicación entre microtejidos sociales y de esta forma genere lazos de solidaridad y acciones conjuntas para superar momentos difíciles.

Si lo anterior se logra, se estarían creando "redes con proyecto", capaces de generar tanto alianzas horizontales con grupos que se encuentran al mismo nivel en cuanto al ejercicio del poder como también verticales, con sectores en "disimetría de poder".

El conflicto y el disenso son elementos que forman parte del entramado de interacciones humanas. Por tanto, no se busca ignorarlos, sino gestionarlos como aspectos que pueden enriquecer la convivencia si se abordan de forma estratégica y desde el respeto a lo diverso.

En este sentido, se asume la corporeidad como código comunicativo. Se considera que a partir del contacto con el cuerpo se puede trascender lo racional y acceder a otras áreas del ser humano, donde no privan la confrontación y el prejuicio. En concordancia con los planteamientos de Porter (1993), la mente no solo se encuentra en el cerebro; también existe una "mente encarnada", que permite interpretar la vida a través del cuerpo. La historia está inscrita en él.

Al hablar de una mente encarnada, el autor expresa que en el cuerpo radica otra forma de pensar el mundo y un espacio donde la memoria viva y activa reside. A partir de los órganos del cuerpo, se puede tener una interpretación de sí mismo y del entorno distinta de la que proviene de las elaboraciones intelectuales. Dicha interpretación, desde lo quinestésico, involucra la subjetividad.

Asimismo, el cuerpo se considera un territorio, un "espacio de acción, representación y memoria" (Chomnalez, 2013, pp. 81-82). Esto habla de un territorio vivo, dinámico y en constante transformación, que por una parte deja evidencias de su memoria 
histórica y por otra esconde algunos de sus rasgos como marca de negociación, adaptación o resistencia.

Ese cuerpo entra en contacto con otros y establece un diálogo, que puede ser de naturaleza intercultural. Por ello cabe aquí hacer referencia a los conceptos de multiculturalismo e interculturalidad.

Respecto al multiculturalismo, Kymlicka (1996) sostiene que, en las sociedades modernas, los distintos grupos demandan un reconocimiento de su identidad, que incluye particularidades culturales. Este reconocimiento implica aspectos de diversidad étnica, pero también otros factores, desde elementos generacionales y de género hasta preferencias sexuales diversas.

Es importante analizar que, si las acciones se limitan a reconocer que existen grupos diferenciados en un colectivo social, esto refuerza la fragmentación, puesto que no se considera de qué manera los grupos diversos pueden relacionarse y convivir. En este caso la diferencia puede verse como amenaza.

Según García Canclini (2004), los conceptos de la multiculturalidad y el multiculturalismo se centran en el reconocimiento de la diferencia, pero carecen de elementos que analicen y construyan formas de interlocución en la diversidad. Por ello, aunque dichos conceptos constituyen la base para el estudio de las diferencias culturales, la realidad del mundo actual -inmerso en un proceso de globalización a través de las migraciones, la evolución tecnológica y mediática- demanda abordar la interculturalidad desde las presentes coyunturas mundiales.

En el caso de Guatemala, la convivencia intercultural enfrenta grandes desafíos, como la problemática de la desigualdad, ligada a la pertenencia étnica. Generalmente, los casos de pobreza coinciden con la procedencia indigena, lo cual tiene por consecuencia que estos sectores de la población no tengan la opor- tunidad de ejercer una ciudadanía plena. Esta desigualdad se hace más fuerte si se suma el género, ya que la pobreza es aún mayor si se es mujer e indígena (Cumes, 2008).

Las grandes disparidades en la distribución de la riqueza y la concentración de los índices de pobreza en las poblaciones indígenas son un fuerte obstáculo para la convivencia en la diversidad. Sin embargo, son necesarios los esfuerzos para el acercamiento entre culturas, puesto que ello podría marcar cambios concretos en la superación de estas brechas, mediante estrategias conjuntas y fortalecimiento del capital social, creación de alianzas y lazos de solidaridad.

Para lograr establecer puentes en la diversidad, primero es necesario cuestionar desde dónde se definen y se construyen las diferencias. En Guatemala históricamente han existido categorias que marcan relaciones dicotómicas: lo mestizo y lo indígena. Pero ¿de dónde surgieron estas clasificaciones?, ¿a qué responden? ¿Qué implica hoy lo mestizo? ¿Qué significa ser maya? ¿Qué es lo mestizo? ¿Quiénes somos?

Adams (1956) explica cómo las categorías mestizoindigena han reforzado tanto las brechas de clase como la valoración y subvaloración de las pertenencias étnicas. Ambas categorías, adoptadas a partir del siglo XVII, se construyen sobre las bases de la exacerbación de ciertas características cercanas a lo mestizo y de la negación de aquellas que tienden hacia el polo opuesto, representado por lo indígena. En consecuencia, lo mestizo está concebido desde la negación de lo indígena.

También se ha utilizado la clasificación de "no indigena" para definir al mestizo, incluso en documentos oficiales. Esto refuerza la negación de lo indígena, pero también niega al mestizo, puesto que esta definición lo concibe a partir de lo que no es y deja de lado aquello que sí lo identifica. En síntesis, las disparidades 


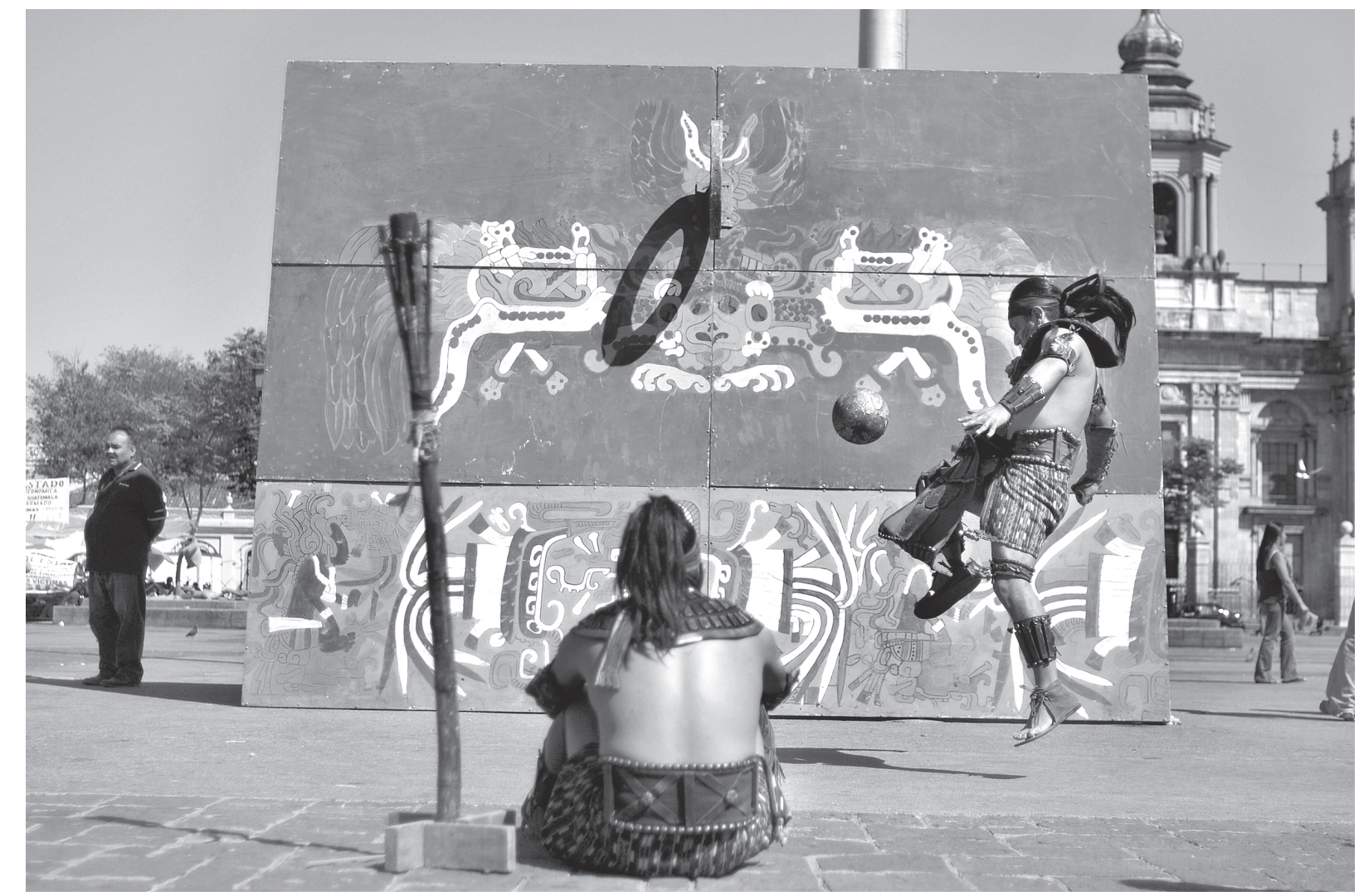

Foto: Eitan Abramovich, AFP. Ciudad de Guatemala, febrero 2009

$3::$

pol propone la aplicación del teatro como una forma de resolución de conflicto en varias etapas. La primera consiste en el consenso de una problemática a trabajar. Esta se representa y el público no es una audiencia pasiva, sino "espectactores" que pueden interferir en la escena, introduciendo cambios. Alguien del público elige actuar un personaje

de los presentados, de forma distinta a como él mismo actúa frente al problema. De esta cuenta, el nuevo agente transforma la situación. Al final, se discute el proceso en asamblea y se proponen acciones concretas y compromisos a asumir entre los participantes. sociales y económicas, los prejuicios y las estigmatizaciones se traducen en discriminación y racismo.

En ese contexto, la presente investigación pretende responder a la necesidad de reconciliación y de cohesión de microtejidos sociales, mediante la creación de un proceso comunicativo que aborde la integralidad y el respeto por la diversidad. Para ello se creó una propuesta metodológica que contempla cuatro ramas artísticas. En cada una de ellas se trabaja con un elemento específico, relacionado con la reflexión identitaria e histórica, la interculturalidad y la convivencia social.

Caminos en el arte, el proceso metodológico

Las artes son el medio más seguro de sustraerse del mundo; son también el medio más seguro de unirse a él.

(Liszt en Morin, 2008, p. 152)

En este trabajo, el arte se concibe a partir de tres elementos esenciales: la subjetividad, la agencia y la postura política. Según Morin (2008), el ser humano transita entre dos estadios: el prosaico, ligado a las actividades "racionales-lógicas-técnicas", y el poético, centrado en las connotaciones más que en las denotaciones, en la emoción y la afectividad, que se traducen en "un estado del alma". En este estado, la persona accede a la relación con el otro, a la convivencia comunitaria, dado que trasciende las relaciones dialécticas, el impulso de imponerse y la necesidad de defensa.

No obstante el conflicto es un elemento central de las relaciones humanas, se pretende, a través del arte, generar un espacio para el conocimiento mutuo en la diversidad y trascender la confrontación para encontrar vías de comunicación integral.

Mediante la técnica del "teatro foro" (Boal, 2009), ${ }^{3}$ los jóvenes abordaron el tema de la discriminación y llegaron a definir acciones de solución. Este y otros temas sensibles fueron tratados de manera abierta y franca, ya que las personas participantes los ubicaron en el terreno de la representación escénica, lo cual permitió llegar a definir soluciones en un campo lúdico. El abordaje de estas problemáticas sensibles es más difícil con técnicas tradicionales de debate, en las que la meta es competir mediante la defensa de un argumento.

El segundo elemento con el cual se fundamenta la visión del arte es la agencia. Thompson (1958) propone el con- 
cepto de agencia humana, y lo define como esa capacidad de las personas para transformar su realidad a partir de la toma de conciencia de su potencialidad como agentes de transformación. Así se supera la creencia de ser y estar determinados por cadenas políticas, sociales o económicas, y se permite a los individuos reconocerse capaces de construir su propia historia.

Thompson considera que el ser humano, a través de un acto de voluntad social o moral, puede superar las limitaciones impuestas por las circunstancias o lo aparentemente inevitable. Sostiene que no son las cosas o los hechos en sí mismos los que configuran la realidad, sino la forma en que la gente se relaciona o reacciona ante estos.

El proceso de creación artística es una herramienta para que los jóvenes desarrollen capacidades de agencia en varias etapas: en la primera, al tomar conciencia de su historia y definirse a sí mismos a partir de una reflexión que parte de su corporeidad y mediante la cual vivenciaron su memoria histórica en constante transformación, decidieron cuáles elementos de su pasado son un trampolín que los impulsa a generar un futuro desde la opción personal y colectiva.

Con base en lo anterior, en una segunda etapa se crearon obras de teatro, danza, música y escritura. Los participantes manifestaron que el hecho de ver sus historias y expectativas de vida reflejadas en sus creaciones les permitió fortalecer su sentido de vida y valores para asumirse como agentes transformadores de su contexto social. ${ }^{4}$

Por último, también se plantea el arte como postura política, considerada como un ejercicio de ciudadanía plena. Por su parte, Mouffe (2001) sostiene que el arte en sí mismo contiene una dimensión política, debido a que su práctica contribuye a dar cuenta de un contexto y del "sentido común", el cual es eminentemente político.
Aquí se trata de la naturaleza política intrínseca al arte que trasciende la intención del artista, dado que su obra inevitablemente dará cuenta del contexto y la coyuntura social que vive.

En la presente investigación se pretende que la dimensión política del arte se haga consciente desde la perspectiva de agencia, para que los jóvenes fortalezcan las alianzas en el tejido social que habitan y puedan generar cambios concretos. Para ello se construyó una metodología a partir de la hermenéutica profunda de Thompson (1998). Esta consta de tres fases. La primera analiza el contexto sociohistórico y las doxas. ${ }^{5} \mathrm{La}$ segunda aborda aspectos que profundizan en las formas simbólicas y en las representaciones sociales. Esta etapa es central en la presente investigación, ya que a mi juicio el proceso de creación artística es la vía para entrar en lo simbólico. La tercera es un análisis y sistematización de las obras artísticas producidas, que se constituyen en soporte material de un momento histórico, identidad y cultura. Esta última parte abarca un análisis de contextos de recepción de las obras. En la figura 1 se presenta una síntesis gráfica del proceso.

Las cuatro áreas artísticas abordadas toman la corporeidad como código de comunicación. Una vez conceptualizado el cuerpo, la praxis de corporeidad se construyó sobre los principios de la somática, ${ }^{6}$ cuyo elemento central es el desarrollo de la conciencia desde el cuerpo. La somática es importante para la generación de conocimiento porque permite entrar en niveles profundos del ser humano, asunto imposible si nos limitamos a considerar únicamente la producción intelectual y el debate oral.

Esta propuesta se centra en prácticas que vinculan la realidad interna-subjetiva y la externa-objetiva, ubicada en el cuerpo como punto focal.

En el contexto guatemalteco se hace imprescindible trabajar a partir del cuerpo, debido a que en varios
$4::$

Información recabada en entrevistas orales y cuestionarios realizados en el parque central de Tactic, Alta Verapaz.

Inmediatamente concluidas las presentaciones, se hicieron entrevistas a los jóvenes que presentaron las puestas en escena para recoger sus percepciones in situ. Luego se aplicaron cuestionarios para profundizar sobre hallazgos relevantes para la investigación.

5::

Según Thompson (1998), las doxas se constituyen en la interpretación que los sujetos atribuyen a las formas simbólicas en la vida diaria: sus creencias que orientan la opinión y los juicios. Se definen como el filtro a través del cual se interpreta la realidad.

"Somática se refiere a los somas de la especie humana, cuyas capacidades sensoriales y motrices escapan relativamente a la determinación por parte de los patrones de comportamiento genéticamente establecidos, la cual permite que sea el aprendizaje lo que determina los procesos de interrelación interna entre conciencia, función biológica y entorno" (Hanna, 1993, p. 187). En danza, Levy y Duke (2003) sostienen que este es un proceso en que la persona elabora una conciencia de sí misma, "dentro de cuerpo", que permite acceder a información individual y colectiva, desde otras esferas humanas que trascienden las elaboraciones intelectuales, permeadas por el pensamiento. 


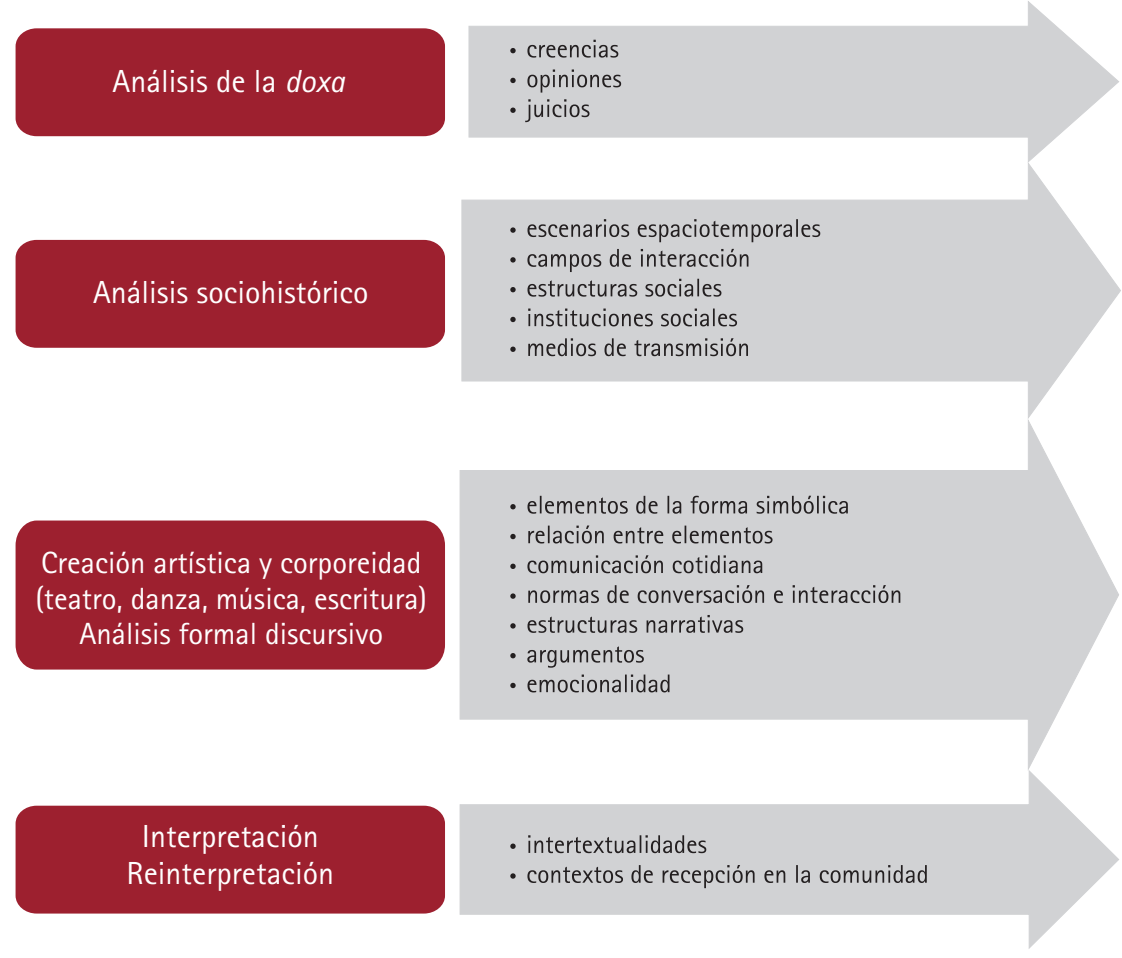

momentos históricos este ha sido portador de mensajes, especialmente los relacionados con advertencias impuestas por el terror, ya sean del Estado o del crimen organizado. La destrucción del cuerpo físico, emocional, moral y espiritual ha sido una estrategia utilizada como arma de guerra. Actualmente estos mensajes siguen vigentes en Alta Verapaz.

Ante esta perspectiva, se justifica el trabajo desde la corporeidad como vía de construcción para una nueva historia y como punto de partida para la generación de convivencia en sociedad. Metafóricamente, el objetivo es contribuir al nacimiento y a la formación de un nuevo cuerpo social.

Otro elemento del proceso metodológico es la consideración de los "universales psicoafectivos", que constituyen rasgos comunes de los seres humanos, independientemente de la cultura y el lugar al que pertenezcan (Morin, 2008). Se agrupan en los siguientes temas:

- rasgos físicos y biológicos compartidos (contacto con el cuerpo)

- tipos de lenguajes compartidos

- elementos comunes de conciencia (valores, motores de acción)

- afectividad
- elementos de reciprocidad e intercambio

- relación nacimiento-vida-muerte

- relación libertad-prohibición

- relación venganza-perdón

- relación individualidad-colectividad

- sacrificio, amistad, relación amor-odio y conflictividad (Morin, 2008).

En cada una de las áreas artísticas se estableció un elemento central para trabajar. El pilar de la danza fue la topología de redes (Rojas, 2008), para la construcción de frases de movimiento. Este concepto, que toma elementos de matemáticas, redes informáticas, psicología y sociología, se basa en el descubrimiento de los nodos que hacen funcionar una red y en construir caminos entre ellos.

Al aplicar este concepto a las estructuras y relaciones sociales, los nodos pueden ser personas o situaciones, desafíos o expectativas de vida. Mientras más caminos existan entre los nodos, mayores posibilidades habrá de que el colectivo social subsista. Así se construyó una danza, como metáfora de la vida social y la expresión de propuestas de convivencia.

Para el área de escritura, se tomó como base el concepto de intertextualidad, entendido como "una relación de reciprocidad entre los textos, es decir, una relación 
entre ellos, en un espacio que trasciende el texto como unidad cerrada” (Villalobos, 2003, p. 137).

El texto abarca no solo la sistematización escrita, sino elementos de la cultura, sociedad, experiencias de vida, creencias, espacios, roles de género, entre otros. Estos múltiples textos interactúan para la interpretación y la creación de realidades. En pocas palabras, nunca se produce un texto aislado, pues este forma parte de una red que lo relaciona con otros textos preexistentes.

Se tomó el cuerpo como primer texto, y a partir de él se formaron redes hacia otros textos como la violencia, la relación familiar, el significado de la tierra, la historia vivida por los jóvenes y la generación anterior, las expectativas de vida, los valores y las representaciones sociales. Con base en esa experiencia, los jóvenes crearon poemas y escritos en prosa, individuales y colectivos, mediante el ejercicio de la escritura automática. $^{7}$

El proceso de creación teatral se centró en el ejercicio de alteridad. Morin (2008) reflexiona sobre los roles sociales que los seres humanos representan en diferentes ámbitos de la vida. Estos roles se instauran como vía de presentación ante el otro, son imágenes que se internalizan y formas de representación ante sí mismo. A través de estos roles sociales se vive un proceso de mímesis que permite encarnar al otro.

La música se concibió como praxis social, como herramienta para "hacer la vida", como un instrumento para construir la sociedad y no solo como un medio para describirla: "La música es, en esencia, la vida en sociedad; contiene en sí misma un concierto entre las condiciones materiales, sociales y culturales en las que se produce" (De Nora, 2003, p. 157).

En esta área, se tomó el latido del corazón como elemento básico, símbolo del ritmo de la vida. De modo que se trabajó con sus características para la composición de obras musicales, a partir de la denominada "música del cuerpo".

La música del cuerpo incluye el pulso (latido del corazón), el tempo (cuán rápido o lento late el corazón), la fluctuación (la aceleración repentina del pulso). También incluye los sonidos que hacemos voluntaria o involuntariamente en el curso de la existencia misma como el llanto de un bebé o el sonido de una madre mientras cocina; los sonidos de una infección en el pecho, los sonidos de una conversación -el tono, los ritmos, el volumen y los tiempos (De Nora, 2003, p. 100).

En las cuatro áreas artísticas, se trabajó en talleres con tres objetivos esenciales: primero, que los jóvenes analicen su contexto sociohistórico a partir del contacto con su corporeidad, de su experiencia de vida individual y del contraste con la vida colectiva en su entorno; segundo, que se reconozcan como sujetos sociales capaces de generar transformaciones que parten de acciones que están a su alcance; tercero, que plasmen una propuesta de convivencia en sociedad, a través de sus obras artísticas.

Como apoyo al proceso de creación artística, se construyeron historias de vida; también se llevaron a cabo conversaciones grupales y cuestionarios con preguntas abiertas.

Las sesiones de guía para la creación de las obras artísticas se hicieron de forma intercalada con reuniones para ensayar de manera autónoma. Esta iniciativa busca conformar grupos comunitarios de creación artística que sigan funcionando luego de finalizado el estudio.

Se realizaron puestas en escena mediante la toma del espacio público. Se eligió el parque central de la
7::

Esta técnica es utilizada en la vanguardia histórica, corriente que dentro del denominado pensamiento manifestario contiene en sí misma "el deseo de instaurar una nueva vida, alterar el orden social y practicar nuevas formas de arte 0 , en otras palabras, el deseo de conquista del poder simbólico, el dominio político y la hegemonía estética" (Gelado, 2008, p. 651). El poeta André Breton fue el precursor de este proceso de escritura, que se centra en una escritura espontánea a partir de una situación o experiencia sensorial, dejando fluir las palabras, sin poner atención en la coherencia entre ellas. El centro es tener vínculo con el inconsciente para que este emerja a partir de dichas palabras que se concretan en el papel y cuya fuente de creación no se centra en lo racional. 
comunidad como escenario para dar vida a representaciones inspiradas en el acto poético, propuesto por Alejandro Jodorowsky, en una encarnación de la poesía en acción: "Salir de la literatura para participar en los actos de la vida cotidiana con la postura estética y rebelde propia de los poetas" (Jodorowsky, 2010, p. 55).

Son acciones que rompen esquemas y que se realizan en espacios y momentos inesperados; con ello provocan un alto en la vida cotidiana, cuyo objetivo es cuestionar la realidad. Estos actos combinan lo lúdico y lo dramático.

El acto poético, al irrumpir en la rutina diaria, es un punto para la creación de una nueva realidad sobre lo existente, para abrir nuevas dimensiones con el fin de interpretar situaciones dadas en el contexto social. Un elemento clave de este accionar es la conciencia. El acto poético presenta una alternativa a la reacción violenta ante los conflictos, porque su enfoque es hacia

$8::$

El flash mobse ha constituido en un nuevo género de la danza, que involucra la expresión artística, las nuevas tecnologías de la comunicación y las denominadas formas no institucionales de teatro o técnicas de teatro invisible. Se ha trabajado como una vía de transformación de los espacios de la ciudad; pertenece a la "retórica peatonal", elabora nuevas trayectorias, constituidas por colectivos populares traducidos en eventos que construyen apropiaciones singulares del espacio público (Gore, 2010, p. 31) Frase expresada por una participante en el taller de música previo a la primera presentación en

el parque como irrupción en el espacio público. Un familiar había sido asesinado el día anterior. Ella manifestó su deseo de interpretar una canción construida colectivamente en defensa de la vida, como vía para la sanación individual y comunitaria. lo constructivo y evita la destrucción. No obstante, implica ciertos choques con el fin de cuestionar lo que la sociedad no ve.

En esta misma línea, en el área de danza se llevó a cabo un flash $m o b,{ }^{8}$ cuyo objetivo, al igual que el del acto poético, es irrumpir en el espacio público al presentar una danza inesperada, a la que se invita a participar a quienes la presencian. También se presentaron, a manera de acto poético, pequeñas obras de escena teatral, escultura viviente, mimos, música y danza.

Los primeros hallazgos

Esta canción me sanó a mí, quiero que también sane a mi comunidad. ${ }^{9}$ (Melgar, 2014)

En cuanto al proceso metodológico, se pudo constatar que el contacto con la corporeidad permite trascender el discurso políticamente correcto. Cuando iniciaron los talleres, se preguntó a los jóvenes sobre aspectos históricos de su comunidad y de su familia, o sobre las situaciones y los desafíos actuales; entonces refirieron ideas vagas, discursos aprendidos o frases que no provenían de su experiencia de vida.

Fue muy diferente la información recabada tras los ejercicios realizados partiendo del cuerpo, concebido como primer territorio habitado. Cada participante identificó un espacio de su cuerpo donde ubicó las marcas de la historia presentes en su vida; posteriormente determinó qué deseaba que permaneciera y qué quería borrar. Ese contacto de la historia en el cuerpo hizo emerger la voz de una profunda conciencia de las huellas históricas comunitarias y familiares, y una postura muy clara ante la situación social actual.

Emergió un contundente rechazo a la violencia, tanto ante las pérdidas constantes de vidas físicas como a la ausencia de seres queridos por los actuales procesos de migración hacia Estados Unidos.

Asimismo, un rechazo a la indiferencia ante la desintegración familiar y un profundo enojo porque el enfrentar constantes peligros aminora el espacio de expansión y de expresión de los jóvenes. Viven bajo presiones constantes, principalmente de sus familias, que mediante un estricto control tratan de protegerlos de las acciones del crimen común u organizado.

Luego de ubicar las huellas de la historia en sus cuerpos, los jóvenes manifestaron frases reveladoras acerca de borrar la desconfianza y la desigualdad que cierran muchas puertas; hacer desaparecer el odio, la violencia y la delincuencia porque son cadenas que apresan e impiden la libre expresión. En contraste, expresaron un deseo profundo de defender la vida y la libertad; un reconocimiento del esfuerzo que sus padres han realizado para brindarles una vida digna, y su anhelo de construir un mejor futuro y tener oportunidades de desarrollo individual y colectivo. 
El testimonio de los jóvenes muestra elementos indispensables para sanar y transformar el tejido social, como la restitución de la confianza entre sus miembros, la necesidad de diálogo y la convivencia en la diversidad, ya que en un mismo contexto existen historias y experiencias de vida distintas. El ejercicio de comprensión de los significados permite, entonces, dialogar con un mismo código y considerar otras perspectivas distintas a la propia.

Los testimonios también hablan de la urgencia de emprender acciones para superar la desigualdad y trascender el odio.

Asimismo manifiestan una postura política que promueve una ciudadanía plena, a través del ejercicio del derecho a la libertad de expresión, y una decisión empoderada sobre los aspectos de la sociedad que desean conservar y aquellos que desean borrar de su vida. Esto marca una redefinición y una transformación identitaria. Los jóvenes cuestionan su contexto social y demandan la toma de conciencia a quienes hacen uso de la violencia en sus distintas manifestaciones.

Estos jóvenes tienen un intenso deseo de transformar su entorno, valoran la familia como pilar de vida, aspiran a ser profesionales y a salir adelante. Durante el proceso, su determinación de vencer temores se hizo evidente en el hecho de expresar sus ideas en público, plasmarlas en obras artísticas y presentarlas en un espacio de la comunidad donde hasta ese momento no se habían dado tales manifestaciones. Estas obras, en las que reflejan sus propias palabras, pensamientos y sentimientos, se constituyen en símbolos que contienen valores como motor de vida y propuestas para la transformación social.

Se construyeron nuevas formas de convivencia en un contexto étnicamente diverso. En los grupos de trabajo, integrados por mestizos, achis, q'eqchi's, pocomchi's, se observó que los participantes encontraron puntos de convergencia (el estudio, la amistad, los liderazgos, incluso el enfrentarse a problemáticas comunes).

También se identificaron algunos puntos de adaptación y negociación identitaria, como el idioma. Los hombres indigenas admitieron con mayor soltura en público el dominio de un idioma maya. El pocomchi" fue la única lengua en la que se compusieron algunas canciones, aun cuando había jóvenes de otras procedencias étnicas. No obstante en Alta Verapaz el grupo q'eqchi' históricamente se ha mantenido como el colectivo dominante, hoy el pocomchi' tiene gran fuerza de pertenencia entre los jóvenes.

En las obras artísticas creadas también se reflejó la relación de estos jóvenes con la tierra. Su concepción sobre ella se ha transformado. Si bien está presente el concepto ancestral de la tierra como madre, como proveedora, el cultivarla no está entre sus expectativas de vida. Valoran el legado de las generaciones anteriores, pero desean un destino distinto al que ellas tuvieron. Estos jóvenes están en contacto constante con las nuevas tecnologías de la comunicación, lo que los expone a otras realidades y también a otros riesgos.

Aunque cuestionan la generación de sus padres, muchos reproducen algunos aspectos que rechazan, como el ejercicio de la autoridad marcada por la imposición. A la vez que protestan ante la necesidad de adoptar normas con las que no están de acuerdo, cuando tuvieron posibilidad de ejercer fuerza de dominio sobre otros, la primera reacción fue de satisfacción, según la idea de "vencer". Fue necesario hacer un proceso de reflexión sobre la importancia del diálogo y de la búsqueda de consensos.

También se manifestaron diferencias marcadas por el género. En la mayor parte de los talleres, hombres y mujeres trabajaron por separado, salvo cuando se 
formaron pequeños grupos para la preparación de las puestas en escena.

En el grupo de danza fue donde participaron menos hombres. Esto responde al imaginario sobre los roles aceptados para hombres y mujeres, ya que en general se considera que la danza es una actividad femenina. Por tanto, los cuatro hombres que participaron en esta área mostraron una actitud de valentía al romper esos esquemas.

En suma, el proceso creativo artístico permite una constante reflexión que confluye en acciones de transformación individual y colectiva. Las obras artísticas resultan un espejo de la vida y traen a la conciencia lo que hasta el momento no se había identificado. Por ejemplo, fue fundamental devolver las frases convertidas en poemas: el hecho de leerse, de verse a sí mismos, permitió a los jóvenes tomar conciencia de sus desafíos, pero también de la fuerza que tienen para salir adelante. Varios manifestaron que era importante encontrar valores y motivos de movimiento en sus propias palabras, salidas del contacto con su corporeidad.

Durante el proceso de creación artística, hubo dos pérdidas de vidas de forma violenta. Una fue la de un familiar de una participante en el área de música y otra fue la de una chica que estaba en el grupo de teatro, que murió por un ataque armado. La chica del familiar asesinado manifestó que una de las canciones que crearon colectivamente fue hecha en defensa de la vida, que su letra la ayudó a sanar la pérdida y que ella cantaba para que su comunidad también sanara.

Entre los cambios surgidos durante el proceso de creación artística, los más valorados fueron el vencer el temor de expresar sus ideas y sus sentimientos, así como de hacerlo públicamente, y el descubrir talentos y habilidades propios que ignoraban, lo cual les permitió conocerse mejor y tener mayor disfrute de la vida.
También manifestaron cambios en cuanto a su relación con sus compañeros, al desarrollar mayor respeto en la interacción y formas de cuidar a los demás. En la expresión artística encontraron "un orgullo porque la gente los escuche” y consuelo ante la pérdida de seres queridos.

La creación artística propició el desarrollo de la convivencia, la comunicación y la libertad de expresión, aspectos que se pueden trasladar como práctica a su contexto social inmediato y luego a colectivos más amplios. Asimismo, los participantes valoraron la posibilidad de ser formadores de otros jóvenes, empleando la metodología de creación artística en otros grupos.

En un contexto que carece de espacios de expresión para jóvenes, la toma del espacio público fue muy importante. Se realizaron puestas en escena en el mismo lugar donde ocurrieron actos violentos, y esto permitió una resignificación de dicho espacio.

Si bien el trabajo de campo de esta investigación aún no está concluido, el proceso ha permitido sistematizar los primeros hallazgos que se han descrito.

El arte ha generado vías de comunicación integrales; ha permitido encuentros humanos que abordan la complejidad de los códigos, entendidos como una comunión profunda de significados en los planos intelectual, emocional, espiritual y de experiencias vitales.:.

Referencias bibliográficas

ACAN/EFE (19 de diciembre de 2010). Gobierno decreta Estado de Sitio en Alta Verapaz. Recuperado el 3 de septiembre de 2013, de Prensa Libre: http://www.prensalibre.com.gt/ noticias/justicia/coba-sitio-estado_0_392960746.html

Adams, R. (1956). Encuesta sobre la cultura de los ladinos en Guatemala. Guatemala, Ministerio de Educación Pública.

Boal, A. (2009). Teatro del oprimido. Juegos para actores y no actores. Barcelona, Alba. 
Cabarrús, C. (2008). Haciendo política desde el sin poder. Bilbao Desclée De Brouwer

García Canclini, N. (2004). Diferentes, desiguales y desconectados. Mapas de la interculturalidad. Barcelona, Gedisa.

Cumes, A. (2008). "Desigualdad social y diversidad cultural", Confluencia. Cuadernos de Observación Activa. (La construccción de comunicación intercultural aplicada), pp. 25-42.

CEDECON (29 de enero de 2011). ¿Caducó el Estado de Sitio? Recuperado el 4 de septiembre de 2013, de El Periódico: http://www.elperiodico.com.gt/es/20110129/opinion/189843/

Chomnalez, V. (2013). "Las derivas de la comunicación: el cuerpo como texto". Revista de Comunicación Vivat Academia. Año XV, núm. 122, pp. 80-91.

Cochoy, M., P. Yac, I. Yaxón, et al. (2007). Cosmovisión maya plenitud de la vida. Guatemala, PNUD.

Constitución Política de la República de Guatemala (reformada por acuerdo legislativo n. $18-93$, del 17 de noviembre de 1993). Guatemala.

COPREDEH. (1998). Acuerdos de Paz. Guatemala, Presidencia de la República de Guatemala.

De Nora, T. (2003). After Adorno. Rethinking music sociology. Cambridge, Cambridge University Press.

García, P., G. Curruchiche y S. Taquirá (2009). Ruxe'el Mayab K'aslemäl. Raíz y espíritu del conocimiento maya. Guatemala, Proémica-Universidad Rafael Landívar.

Geertz, C. (2001). La interpretación de las culturas. Barcelona, Gedisa.

Gelado, V. (2008). "Un 'arte de la negación'. El manifiesto de vanguardia en América Latina". Revista Iberoamericana, Vol. LXXIV, núm. 224, pp. 649-666.

Gore, G. (2010). "Flash Mobe Dance and the territorialisation of urban movement". Anthropologycal notebooks 16, pp. 125-131.

Gularte, E. (2009). "La comunicación en la sociedad del conocimiento: desafios para la universidad". XIII Encuentro latinoamericano de facultades de comunicación social. FELAFACS, La Habana, pp. 2-10.

Jodorowsky, A. (2010). Psicomagia. Madrid, Siruela.

Kymlicka, W. (1996). Ciudadanía multicultural. Barcelona, Paidós.

Ministerio Público (13 de junio de 2013). Capturados los responsables de violaciones cometidas en Alta Verapaz. Recuperado el 5 de septiembre de 2013, de Ministerio Público: http://www.mp. gob.gt/2013/06/capturados-los-responsables-de-violacionescometidas-en-alta-verapazl

Morin, E. (2008). El Método 5. La humanidad de la humanidad. Madrid, Cátedra Teorema.
Mouffe, C. (2001). Every form of art has a political dimension. (R. Deutsche, B. Joseph y T. Keenan, entrevistadores). Recuperado de Grey Room 02: http://pdflibrary.files.wordpress.com /2008/07/mouffe_interview.pdf

ODAHG. (1997). Testimonio colectivo 9, declarante 6, p. 4. Guatemala.

Papalini, V. (2007). "Hermenéutica y comunicación: Hacia una dialógica crítica". Revista Latinoamericana de Ciencias de la Comunicación (ALAIC), año IV, núm. 6, pp. 22-31.

Porter, R. (1993). "Historia del cuerpo revisada", en P. Burke, Formas de hacer historia. Madrid, Alianza, pp. 255-286.

Redacción (25 de mayo de 2011). El auxiliar fiscal asesinado investigaba caso de los Zetas. Recuperado el 4 de septiembre de 2013, de El Periódico: http://www.elperiodico.com. $\mathrm{gt} / \mathrm{es} / 20110525 /$ pais/195855/?tpl=73\&theight=500\& $\mathrm{twidth}=600$

Rojas, D. (2008). Acerca de la visualización topológica de redes. Recuperado el 21 de mayo de 2012, de https://www. google.com.gt/\#hl=esCtsclient=psyabEtq=Acerca+de+la+visu alizaci\%C3\%B3n+topol\%C3\%B3gica+de+redes+Daniel+Roja s\%2C+datos+bibliogr $\%$ C $3 \%$ A 1 ficosEtoq=Acerca+de+la +visu alizaci\%C3\%B3n+topol\%C3\%B3gica+de+redes+Daniel+Roja $s \% 2 \mathrm{C}+$ datos+bibliogr $\% \mathrm{C} 3 \% \mathrm{~A} 1$ ficos $\mathrm{Ctaq}=\mathrm{f}$

Sam, E., y A. Tax (28 de junio de 2013). MP analiza caso de linchamiento. Recuperado el 15 de julio de 2013 de Prensa Libre: http://www.prensalibre. com/alta_verapaz/MP-analizacaso-linchamiento_0_946105393.htm

Taracena Arriola, A. (s. f.). Guatemala: del mestizaje a la ladinización 1524-1964. Guatemala, Centro de Investigaciones Regionales de Mesoamérica (CIRMA). Recuperado el 26 de junio de 2012, de http://repositories.lib.utexas.edu/bitstream/handle/2152/4058/ arriola.pdf?sequence $=2$

Tax, A., y E. Sam (19 de diciembre de 2010). Cobaneros aprueban Estado de Sitio en Alta Verapaz. Recuperado el 18 de junio de 2013 de Prensa Libre: http://www.prensalibre. com/noticias/justicia/Cobaneros-aprueban-Sitio-AltaVerapaz_0_392960828.html

Thompson, E. (1958). "Agency and Choise I. A reply to Criticism". The New Reasonern. ${ }^{\circ}$, pp. 89-106.

Thompson, J. (1998). Ideología y cultura moderna. Teoría crítica social en la era de la comunicación de masas. México Universidad Autónoma Metropolitana.

Villalobos, I. (2003). "La noción de intertextualidad en Kristeva y Barthes". Filosofía, XLI (103), pp. 137-145.

Yax, R. (13 de junio de 2013). Violaciones en Alta Verapaz. Recuperado el 15 de julio de 2013 de Noti Real GT:http://notire algt.blogspot.com/2013/06/violaciones-en-alta-verapaz.html 